Arch. hist. jap. Vol. 17, n. 2 (Juni 1959).

S. $261-277$.

Anat. Inst. d. Med. Fak., Univ. Okayama (Vorstand: Prof. M. SEKI).

\title{
Beobachtung der in den Bindegewebszellen aufgenommenen Markscheidensubstanz.
}

\author{
結織細胞に取られた髄鞘物質の観察.
}

Hiroshi YASUHARA 安 原弘.

(Eingegangen am 17. März 1959.)

Die Veränderungen von in den Bindegewebszellen aufgenommenen lipoiden Substanzen wurden von KŌYAMA (1951) beobachtet. Er injizierte Lecithin u. a. in die Unterhaut der Maus und untersuchte Zellen in ihr nach Fixierung in Formalin und Färbung mit lipoidfärbendem Viktoriablau 4R von GRÜBLER. Später beobachtete FUJISAWA (1956) an lebenden Bindegewebszellen der Maus, wie sich die in ihnen phagocytierten Milchkügelchen verändern, wobei er lipoidfärbendes Viktoriablau von MERCK benutzte. Er fand, daß mit dem Lipoidfärber die Milchkügelchen in den Zellen anfangs kaum, später aber immer stärker färbbar werden.

Ich unternahm eine gleichartige lebende Färbung der Markscheidensubstanz phagocytierten Bindegewebszellen. Die Markscheidensubstanz besteht hauptsächlich aus Lipoid, das man Myelin nennt. Das Myelin quillt bekanntlich im Wasser auf.

\section{Material und Methode.}

Der einem Kaninchen entnommene Nervus ischiadicus wurde zerschnitten, in dem Mörser gerieben und mit 5 facher Menge von physiologischer Kochsalzlösung verdünnt. Das Filtrat durch geschichtete Gazen wurde 3 Minuten lang zentrifugiert. Man nahm die Emulsion aus der Mittelschicht, in welcher die Emulsionsteilchen beinahe gleichgroß waren. Die Teilchen bestehen hauptsächlich aus Myelin. Man injizierte $0.1 \mathrm{cc}$ Emulsion in die Unterhaut des Rückens von Mäusen, tötete sie nach 6 Stunden und 1, 3, 5 und 10 Tagen und nahm kleine Gewebestückchen aus von dem injizierten Ort um mehrere Millimeter entfernten Stellen. Das Stückchen wurde immer im Laufe von 10 Sekunden leicht auf dem Objektglas ausgedehnt und ein Tropfen von 10\%igem Formalin hinzugefügt. Die Bindegewebshäutchen wurden weiter für 5 Studen lang in großer Menge von 10\%igem Formalin fixiert.

Die Farblösungen waren folgende. 1. Alkoholische 0.2\%ige Lösung von Viktoriablau 4R (von GRÜBLER) wurde kurz vor dem Gebrauch mit destilliertem Wasser 20 fach verdünnt. Die Lösung enthielt endgültig $0.01 \%$ iges Viktoriablau 4R und 5\%igen Alkohol. 2. Alkoholische 0.2\%ige Lösung von Irisolechtviolett BBN (von BAYER) wurde kurz vor dem Gebrauch mit destilliertem Wasser etwa 7 fach verdüunt. Die erhaltene Lösung enthielt 0.03\%iges Irisolechtviolett BBN und 15\%igen Alkohol. 3. Gesättigte Lösung von Sudanschwarz B (von MERCK) 
mit 25\%igem Alkohol. 4. Gesättigte Lösung von Sudan III (von ISHIZU) mit 60\%igem Alkohol.

Die Häutchenpräparate wurden nach dem Auswaschen in das Lösungsmittel des Farbstoffes, d. i. 5, 15, 25 bzw. 60\%igen Alkohol, 2-3 Minuten lang getaucht und dann mit Viktoriablau 4R für 10 Minuten, mit den anderen Farbstoffen aber für 40 Minuten gefärbt, immer bei $37^{\circ} \mathrm{C}$ in großer Menge der Farblösung. Dabei ließ man das Objektglas mit dem Gewebshäutchen nach unten in die Farblösung eingelegt. Das mit Sudan III gefärbte Präparat wurde nach der Mikroskopierung auch mit Viktoriablau 4R-Lösung nachgefärbt. Die gefärbten Präparate wurden alle mit Wasser gewaschen und im APÁTHYschen Gummisyrup eingeschlossen.

Andererseits färbte man die Gewebshäutchen nach der in der Histologie üblichen WEIGERT-KULTSCHITZKYschen Markscheidenfärbungsmethode.

Den obigen Untersuchungen liefen Vorversuche voraus, in welchen die Emulsion von Markscheidensubstanz mit dem zehnten Teil Formalin versetzt wurde, um die Markscheidensubstanz unmittelbar zu fixieren. Eine geringe Menge der Emulsion wurde im Reagenzglas mit 5 Teilen Farblösung gemischt und bei $37^{\circ} \mathrm{C}$ stehen gelassen, und zwar bei Viktoriablau 4R 10 Minuten und bei den anderen Farbstoffen 40 Minuten lang. Zur Untersuchung brachte man einen Tropfen von ihnen auf das Objekt über.

\section{Ergebnisse und Auswertung.}

\section{A. Vorversuch.}

Es wurde konstatiert, daß die Myelinteilchen in der Emulsion mit Viktoriablau 4R schwach, mit Irisolechtviolett BBN kaum, aber mit Sudanschwarz B stark blau und mit Sudan III auch stark orangegelb gefärbt werden. Viktoriablau $4 \mathrm{R}$ und Irisolechtviolett BBN sind, worauf SEKI (1956) aufmerksam gemacht hat, mittelstark polar und als lipoidfärbende Farbstoffe ausgezeichnet. Die bessere Färbung der Myelinteilchen mit Sudanschwarz B und Sudan III als mit Viktoriablau 4R und Irisolechtviolett BBN beruht offenbar darauf, daß diese Teilchen schwach polare Lipide* reichlich enthalten. Zu bemerken ist aber auch in diesem Versuche, daß die in der Emulsion befindlichen Teilchen im Vergleich zur natürlichen Markscheidensubstanz bei weitem schwächer polar geworden sind, indem stärker polare, wasserlösliche Bestandteile sich weitgehend in dem Lösungsmittel aufgelöst haben.

\section{B. Hauptteil des Versuches.}

a) Befunde der Bindegewebszellen im normalen Gewebe.

Viktoriablau $4 R$ ist schwach basisch und färbt neben den Lipoiden oft mehr oder weniger stark saure Eiweißsubstanzen. Dieser Farbstoff färbt nicht wenige paraplasmatische Einschlüße im Cytoplasma der Fibrocyten, Fibrohistiocyten und Histiocyten. Im Cytoplasma der Fibrohistiocyten und Histiocyten erscheinen zuweilen mäßig grobe Granula stark gefärbt. Die Kernmembran der Bindegewebszellen

* Unter den Lipiden versteht man die Lipoide und Fette. 
färbt sich etwas stärker als das umgebende Cytoplasma (Abb. 1). An der inneren Fläche der Kernmembran erscheinen feinste, stark gefärbte Granula. Die Granula der Mastzellen werden ganz besonders stark gefärbt, welche man sehr leicht von anderen unterscheiden kann.

Schwach saures Irisolechtviolett $B B N$ färbt das Lipoid, hat aber fast keine Affinität zu Eiweißsubstanzen. Bei näherer Beobachtung werden im Cytoplasma der Fibrocyten und Fibrohistiocyten als Mitochondrien aufzufassende Stäbchen und Körnchen erkennbar. Das Innere des Zellkerns ist mit diesem sauren Farbstoff nur blaß färbbar (Abb. 6). Die acidophilen Granula in den leukocytären Zellen werden dunkel gefärbt (Abb. 10), dagegen bleiben die der Mastzellengranula ungefärbt.

Mit Sudanschwarz $B$ erfolgt die Färbung der Bindegewebszellen wie bei Irisolechtviolett BBN (Abb. 11-14). Die Granula der Mastzellen färben sich. Die Färbbarkeit der acidophilen Granula der leukocytären Zellen ist schwächer als bei Irisolechtviolett BBN.

Sudan III färbt, abgesehen von den Fettzellen, fast keine Bindegewebszellen, nur daß unter den Fibrohistiocyten und Histiocyten wenige damit anzufärbende Tröpfchen auftreten.

Nach der WEIGERT-KULTSCHITZKYschen Färbung zeigen sich oft in den Fibrohistiocyten und Histiocyten schwer zu entfärbende dunkelblaue Granula. Die Granula der Mastzellen bleiben auch gefärbt.

\section{b) Befund 6 Stunden nach der Injektion.}

Durch die Einführung der Emulsion der Markscheidensubstanz wird die fibrohistiocytäre Zellgemeinschaft gereizt, und viele Fibrocyten kugeln sich ab und wandeln sich zu Fibrohistiocyten um, aber auch ein Teil von Fibrohistiocyten zu Histiocyten (Abb. 2 und 7). Im Cytoplasma der Fibrohistiocyten und Histiocyten sieht man phagocytierte kleine Myelinteilchen (Abb. 2, 7, 11, 15 und 19).

Die Myelinteilchen in und um die Zellen werden mit Viktoriablau $4 R$ schwach gefärbt (Abb. 2). Nur gelegentlich bemerkt man damit stärker färbbare Teilchen in den Zellen.

Die Myelinteilchen färben sich mit Irisolechtviolett $B B N$ viel schwächer als mit Viktoriablau, und man findet damit mäßig stark färbbare nur vereinzelt, besonders im Innen der Zellen (Abb. 7).

Mit Sudanschwarz B werden die Myelinteilchen in und um die Zellen stark gefärbt (Abb. 11).

Sudan III färbt die Myelinteilchen fast so gut wie Sudanschwarz B (Abb. 15).

c) Befund 1 Tag nach der Injektion.

Die Fibrocyten enthalten oft zahlreiche Myelinteilchen. Ihre Vermehrung ist viel ausgesprochener in den Fibrohistiocyten und Histiocyten. Ein Teil von den Teilchen verschmelzen miteinander und bilden größere Formen.

Die Myelinteilchen in den Zellen nehmen an Färbbarkeit mit Viktoriablau $4 R$ beträchtlich zu. $\mathrm{Zu}$ bemerken ist dabei, daß die Teilchen außerhalb der Zellen nicht so stark färbbar sind wie die in den Zellen (Abb. 3). Das beruht offenbar darauf, daß im Zellinneren die aus Lipoiden und Eiweißen bestehenden Myelinteilchen durch die Verdauung gespaltet werden und die Lipoide von der Verbindung 
befreit und sozusagen demaskiert werden. Dies ist aus den eingangs erwähnten Untersuchungen von FUJISAWA (1956) sowie von HASHIMOTO (1957) verständlich. Nach der letzteren nimmt die mit Formalin leicht fixierte Markscheide des peripheren Nerven des Frosches durch Wirkung der Ultraschallwellen an Färbbarkeit mit Viktoriablau beträchtlich zu.

Auch mit Irisolechtviolett $B B N$ werden die in den Zellen aufgenommenen Myelinteilchen stärker färbbar, aber nicht so beträchtlich wie bei Viktoriablau 4R (Abb. 8).

Bei Sudanschwarz B, Sudan III und WEIGERT-KULTSCHITZKYscher Färbung in dem Zeitablauf von der 6. bis 24. Stunde tritt keine regelmäßige Änderung der Färbbarkeit der Myelinteilchen ein (Abb. 12, 16 und 20).

d) Befund 3 Tage nach der Injektion.

Im Zelleib der Fibrohistiocyten und Histiocyten vermehren sich feine und grobe Teilchen beträchtlich (Abb. 4, 9, 13, 17 und 21). Aber die Teilchen außerhalb der Zellen nehmen an Zahl ab. In diesem Stadium entstehen zahlreiche Vakuolen in den Zellen. Bemerkenswert sind die von Vakuolen umgegebenen Myelinteilchen.

Viktoriablau $4 R$ färbt alle Myelintəilchen in und um die Zellen stark blau (Abb. 4).

Mit Irisolechtviolett $B B N$ werden nun Myelinteilchen, besonders die in den Zellen, weitgehend stärker violett färbbar (Abb.9). Man sieht hier oft solche Myelinteilchen, welche fleckig schwächer und stärker gefärbt werden.

Die Färbbarkeit der Myelinteilchen mit Sudanschwarz $B$ bleibt wie vorher (Abb. 13).

Die Färbbarkeit der Myelinteilchen mit Sudan III wird etwas schwächer. Durch die Nachfärbung mit Viktoriablau 4R erscheint ein Teil der rot gefärbten Myelinteilchen bläulichrot (Abb. 17), eine Tatsache, die uns das Freiwerden von schwächer polaren Lipoiden zeigt.

Nach der WEIGERT-KULTSCHITZKYschen Färbung werden die groben Teilchen in den Zellen dunkel gefärbt (Abb. 21).

e) Befund 5 Tage nach der Injektion.

Die Veränderung des Gewebes klingt ab, und die Zahl der Histiocyten geht zurück, dagegen vermehren sich die Fibrocyten. Die Myelinteilchen in den Fibrohistiocyten und Histiocyten nehmen an Größe und Zahl ab, dabei erscheinen große Vakuolen im Cytoplasma. Die Vakuolen schließen oft Myelinteilchen ein (Abb. 5, 10, 14 und 18).

Die Färbung der meisten Myelinteilchen erfolgt, Sudan III-Färbung ausgenommen, wie nach 3 Tagen. Die Färbbarkeit der Myelintəilchen mit Sudan III ist viel schwächer als vorher (Abb. 18), dagegen ist die mit Viktoriablau $4 R$ verstärkt. Mit Irisolechtviolett $B B N$ werden die Myelinteilchen hier auch oft fleckig stärker und schwächer gefärbt (Abb. 10).

f) Befund 10 Tage nach der Injektion.

Das Gewebebild wird wieder wie in früheren Zuständen. In seltenen Fällen bleiben in den Fibrohistiocyten und Histiocyten einige noch nicht verdaute Myelinteilchen, welche sich mit den obigen Farbstoffen färben. 


\section{Zusammenfassung.}

Nach der Injektion der aus der Markscheidensubstanz von Nerven erhaltenen Emulsion in die Unterhaut der Maus wurden die zeitlichen Veränderungen der in den Bindegewebszellen aufgenommenen Myelinteilchen bezüglich der Größe und der Färbbarkeit mit lipoidfärbenden Farbstoffen untersucht.

1. Durch die Reize der Emulsioninjektion vermehren sich Fibrohistiocyten und Histiocyten. Die Zahl und Menge der phagocytierten Myelinteilchen steigt am 3. Tage nach der Injektion aufs höchste, danach werden sie durch Verdauung verringert. Im Laufe von 10 Tagen verschwinden die Myelinteilchen.

2. Die Myelinteilchen in den Zellen sind nach 6 Stunden mit schwach basischem Viktoriablau 4R schwach anzufärben, und nach 1 Tag bis zum Verschwinden immer stärker. Sie werden aber mit schwach saurem Irisolechtviolett BBN nach 6 Stunden kaum, nach 1 Tag schwach und erst nach 3 Tagen stark gefärbt. Die stärkere Färbbarkeit von Viktoriablau $4 \mathrm{R}$ geht offenbar darauf zurück, daß der Farbstoff außer den Lipoiden auch Eiweißsubstanzen zu färben fähig ist.

3. Sudanschwarz B ist ein schwach saurer Farbstoff und färbt nicht nur Lipoide sondern auch echtes Fett, so daß es von Anfang an bis zum Ende die Myelinteilchen in den Zellen färben kann.

4. Das am schwächsten polare Sudan III färbt Myelinteilchen in den Zellen anfangs stark, aber danach immer schwächer, weil offenbar die Myelinteilchen sich spalten und stärker polar werden.

\section{内 容 自 抄.}

神経の髄鞘物質から作った乳濁液を二十日鼠の背部の皮下に注射し，以後時間 の経過を追って結織細胞内に取られた粒子の形と類脂質を染める染料での染色性 の変化を観察した.

1. 乳濁液の注射の刺戟により，組織に線組球と組織球が増す。細胞に胞食さ れた䊀子の数と量は注射の 3 日後に最高に達し，それから消化により減少し，10 日後には殆んどなくなる。

2. 弱塩基性のビクトリア青 $4 \mathrm{R}$ では細胞に取られた粓子は 6 時間後に弱く染 まり，1 日後からはそれが消失するまで強く染まる，弱塩基性であるイリゾール エヒト紫BBN では粒子は注射の 6 時間後にはまだ殆んど染まらず，1日後に弱く 染まり始め, 3 日後に漸く強く染まるようになる。両染料の染色差は前者が類脂 質のほかに蛋白質をあ染めることにあると思える。

3. ズダン黒 B は類脂質とともに真性脂肪をあ染める弱酸性染料であり，初め から終りまで細胞内に取られた精子を強く染める。

4. 殆んど無極のズダン III は細胞内に取られた粒子を初めには強く染めるが, 後にはよく染めぬようになる。乙れは粒子が分解し，その極性が強まるためであ ると思える。 


\section{Literatur.}

Fujisawa, Ky.: Untersuchung über die Veränderungen der Form und Färbbarkeit bei den in und außerhalb der Zellen vorhandenen Milchkügelchen nach Einspritzung von Kuhmilch in die Unterhaut der Maus. Arch. hist. jap. 9 (1956). - Hashimoto, K.: Veränderungen der Struktur und Färbbarkeit der mit hochfrequentem Schall behandelten markhaltigen Nervenfasern des Frosches. Arch. hist. jap. 13 (1957). — Kōyama, Y.: Untersuchungen über die Lipoidaufrahme der Zellen des fibrohistiocytären Systems; eine Methode zum Nachweis der Lipoidsubstanzen in Zellen mit Viktoriablau. Arch. hist. jap. 2 (1951). - Der zeitliche Verlauf der Lipoidaufspeicherung und -verdauung in den Zellen des fibrohistiocytären Systems. Arch. hist. jap. 2 (1951). - Seki, M.: Methodik zur Färbung der freien dipolhaltigen Lipoide in ihren nátürlichen Zuständen. Arch. hist. jap. 10 (1956). 
Tafelabbildungen. 


\section{Erläuterung zu den Tafelabbildungen.}

Abb. 1-18. Häutchenpräparate von mit Formalin fixiertem subkutanen Gewebe der Maus.

Abb. 1-5. Färbung mit Viktoriablau 4R. $900 \times$.

Abb. 1. Normales subkutanes Gewebe. Man sieht im Cytoplasma zahlreiche fein gefärbte Granula. Die außenhalb der Zellen vorhandenen, stark gefärbten groben Granula sind aus den Mastzellen.

Abb. 2. 6 Stuunden nach der Injektion der Myelinemuision. Die Myelinteilchen in und um die Zellen werden schwach gefärbt.

Abb. 3. 1 Tag nach der Injektion. Die Myelinteilchen in den Histiocyten werden stark gefärbt.

Abb. 4. 3 Tage nach der Injektion. Die eingenommenen Myelinteilchen in den Histiocyten werden stark gefärbt.

Abb. 5. 5 Tage nach der Injektion. In den Histiocyten finden sich zahlreiche stark gefärbte Myelinteilchen und reichliche Vakuolen. 
H. YASUHARA (1)
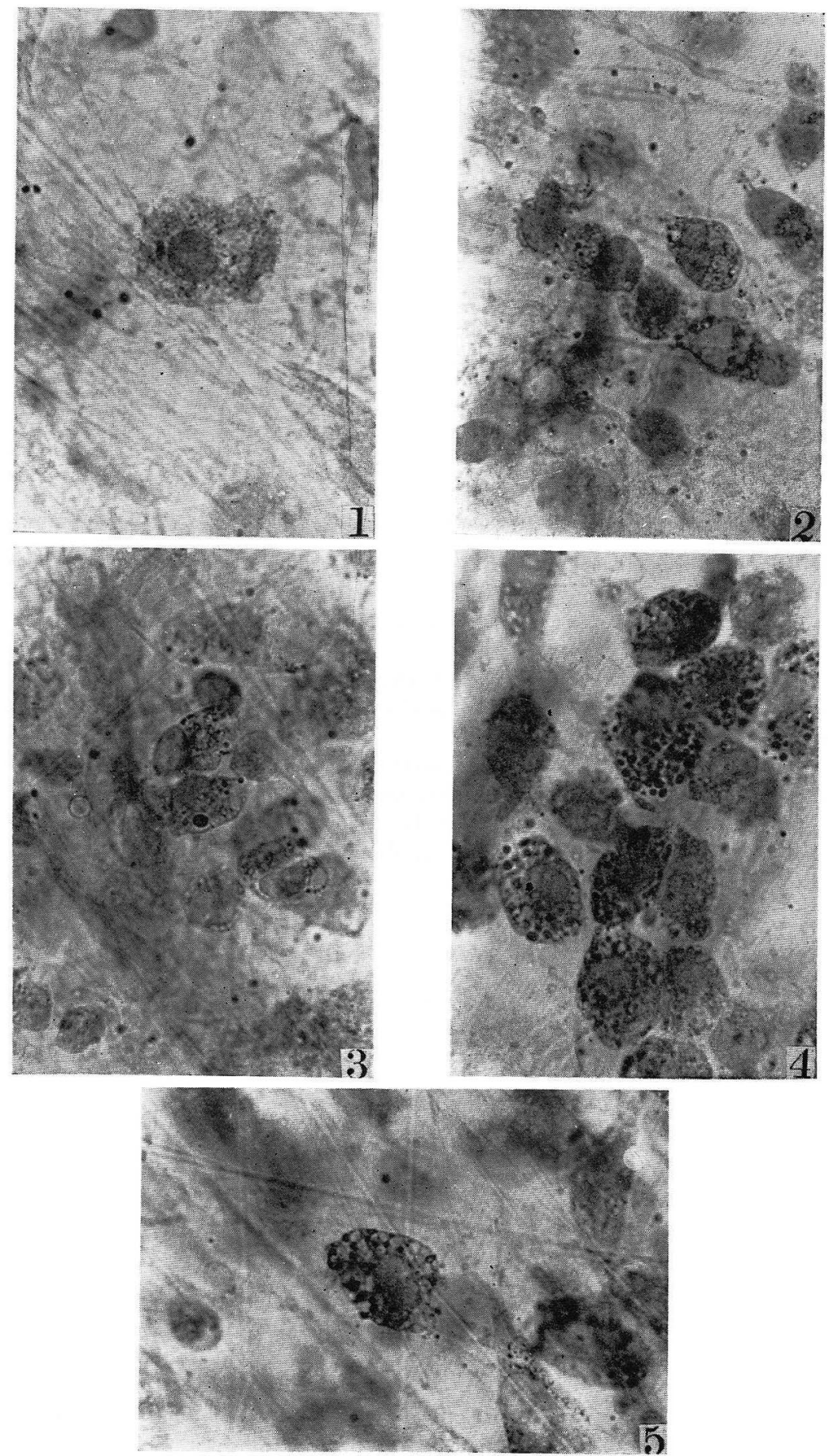
Abb. 6-10. Färbung mit Irisolechtviolett BBN. $900 \times$.

Abb. 6. Normales subkutanes Gewebe. Feine Granula in den Histiocyten färben sich nur schwach.

Abb. 7. 6 Stunden nach der Injektion. Die Myelinteilchen in und um die Zellen färben sich nicht stark.

Abb. 8. 1 Tag nach der Injektion. In den Fibrohistiocyten und Histiocyten finden sich schwach gefärbte Myelinteilchen. Im Mittelteil der Abbildung liegt eine acidophile leukocytäre Zelle.

Abb. 9. 3 Tage nach der Injektion. Im Cytoplasma der Histiocyten sieht man fleckig gefärbte Myelinteilchen von kleinerem oder größerem Ausmaß.

Abb. 10. 5 Tage nach der Injektion. In einer Histiocyten sieht man $M_{y}$ clinteilchen enthaltende große Vakuolen. Am linken Rand der Abbildung eine acidophile leukocytäre Zelle. 
H. YASUHARA (2)
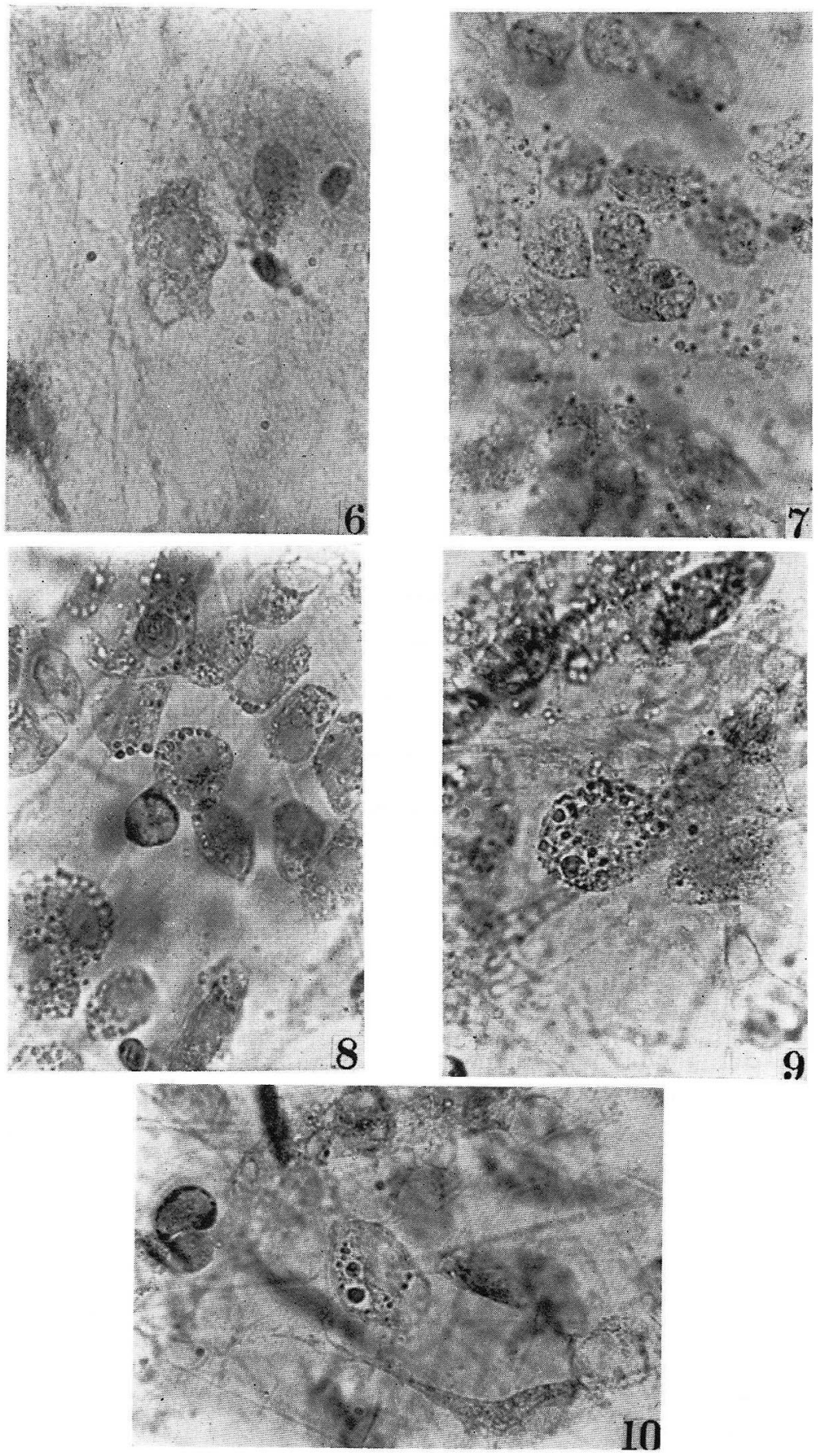

271 
Abb. 11-14. Färbung mit Sudanschwarz B. $900 \times$.

Abb. 11. 6 Stunden nach der Injektion. Außerhalb der Zellen befinden sich viele stark gefärbte Myelinteilchen.

Abb. 12. 1 Tag nach der Injektion. Innen und außen an den Zellen liegen stark gefärbte Myelinteilchen.

Abb. 13. 3 Tage nach der Injektion. Fibrohistiocyten und Histiocyten mit zahlrei. chen phagocytierten Myelinteilchen.

Abb. 14. 5 Tage nach der Injektion. In einem Histiocyten sieht man große Vakuolen, die zahlreiche Myelinteilchen einschließen. 
H. YASUHARA (3)
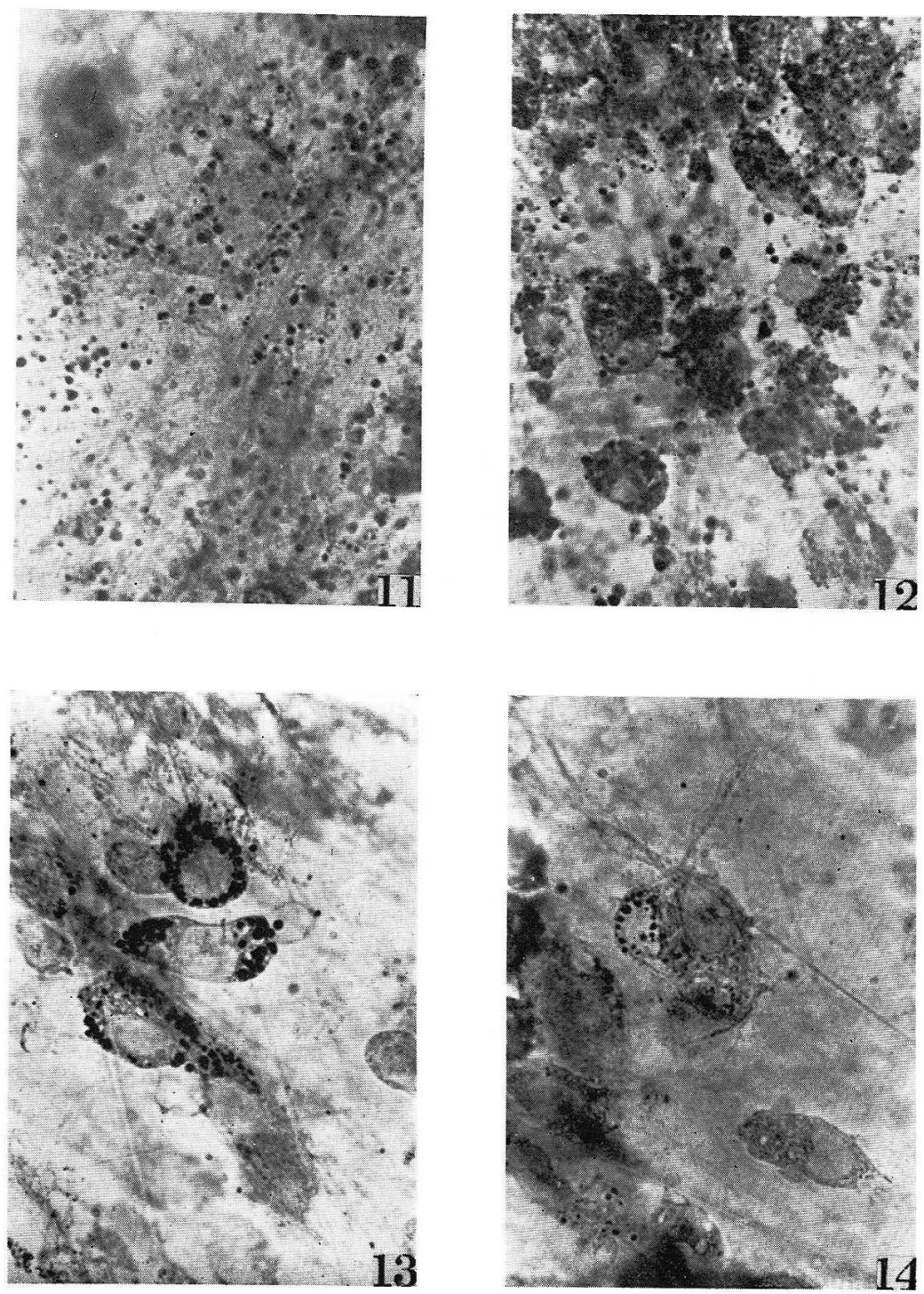
Abb. 15-18. Färbung mit Sudan III. Nachfärbung mit Viktoriablau 4R. 900×.

Abb. 15. 6 Stunden nach der Injektion. In der Wirklichkeit färben sich die Myelinteilchen orangegelb, und die anderen Substanzen in den Zellen blau.

Abb. 16. 1 Tag nach der Injektion. Im originalen Präparat erscheinen die Myelinteilchen in den Zellen orangegelb, und die anderen Substanzen blau.

Abb. 17. 3 Tage nach der Injektion. Die Myelinteilchen in den Zellen erscheinen im originalen Präparat orangegelb oder bläulichorangegelb, und die anderen Substanzen blau.

Abb. 18. 5 Tage nach der Injektion. Im originalen Präparat ist ein Teil der Myelinteilchen in den Zellen orangegelb gefärbt, und die übrigen Myelinteilchen und alle anderen Substanzen blau. 
H. YASUHARA (4)
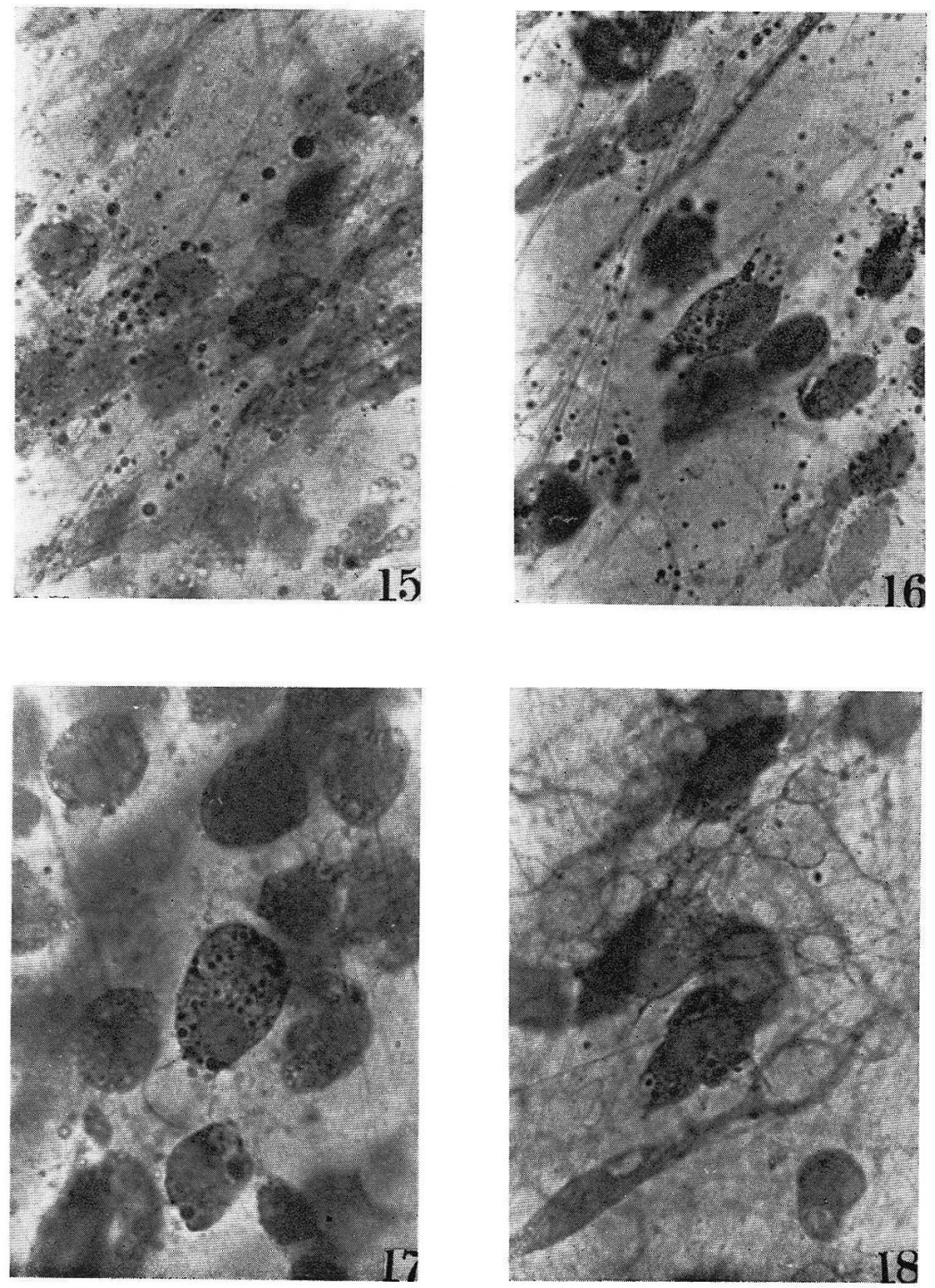
Abb. 19-22. Färbung nach der WEIGERT-KULTSCHITZKYschen Markscheiden. färbung. $900 \times$.

Abb. 19. 6 Stunden nach der Injelition. Im Cytoplasma der Histiocyten finden sich stark gefärbte Myelinteilchen.

Abb. 20. 1 Tag nach der Injektion.

Abb. 21. 3 Tage nach der Injektion.

Abb. 22. 5 Tage nach der Injektion. 
H. YASUHARA (5)
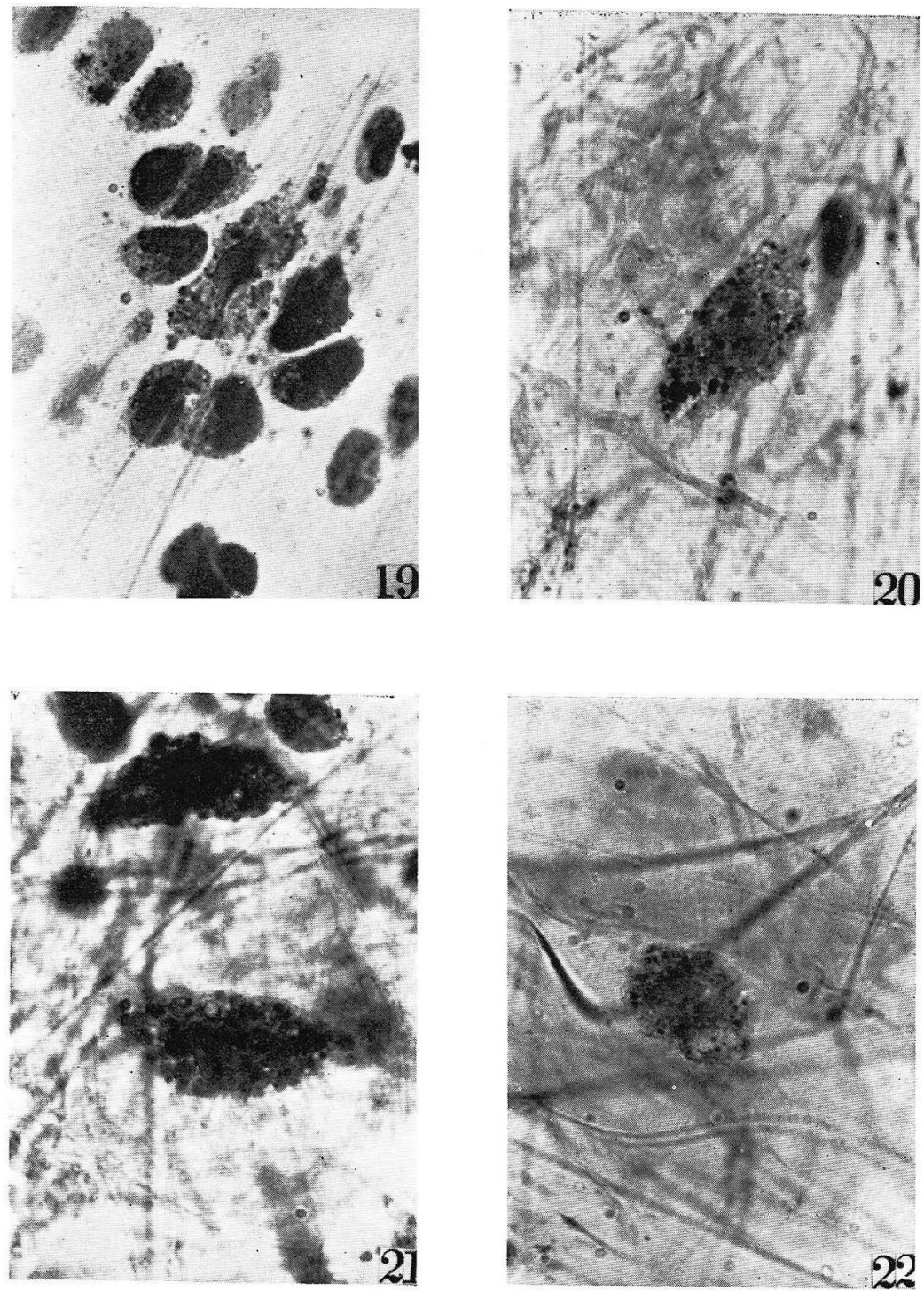